\title{
EL LENGUAJE POSMODERNO
}

\author{
(POSTMODERN LANGUAGE)
}

Andrés García, Arquitecto. Profesor de la Facultad de Arquitectura - Universidad del Zulia MARACAIBO. VENEZUELA

RESUMEN

El presente artículo hace una propuesta para el análisis sistemático de la modernidad y posmodernidad, a través de los diferentes puntos del trabajo. Se inicia con el lenguaje, no sólo verbal, sino el comunicacional de todo fenómeno cultural y especificamente el de la arquitectura.

\section{SUMMARY}

This article is a proposal for the systematical analysis of modernity and postmodernity, through the different stages of work. It begins with the language, not only verbal but also communicational of all cultural phenomena and specifically of Architecture.

\section{EL LENGUAJE}

"In principio erat Verbum et Verbum erat apud Deum et Deus erat Verbum" ("En el principio era El Verbo y EI Verbo estaba frente a Dios y EI Verbo era Dios"). Con estas aseveraciones se inicia el Cuarto Evangelio del Nuevo Testamento, allí sin rodeos, Juan el Evangelista presenta la simbiosis entre la palabra divina y el Ser Supremo. Dios y su expresión son al unísono Ser y Voz Eterna. Se reflexiona sobre Dios mediante los términos que lo representan y se adquiere conciencia de él en un proceso donde la voz refleja su totalidad ecuménica.

La palabra, el signo y el símbolo, han sido desde la antigüedad, las más permanentes expresiones del ser. Como hechos objetivos y concretos, transitan libremente por el devenir en procura de infinitas interpretaciones. Palabras, signos y simbolos, son el legado trascendente y a la vez la invitación a la poética, a la "poiesis", a la creación. Palabras, signos y símbolos, son testimonios, a la vez que excitan el deseo por imprimir en el presente la huelle perenne. De alli que el lenguaje es medio y simiente del discurso que perpetúa el pensamiento, y en tal sentido gesta el afán por construir la impronta imperdurable. Es el hombre construyendo su historia.
Así la lingüística, en función de estudiar estas continuas mutaciones, ha distinguido perfectamente desde Ferdinand de Saussure a Noam Chomky, dos categorias en esta ciencia: la primera - -Lengua" 0 "Performance"-, de la segunda -"Habla" o "Competence"-(1), con el objeto de diferenciar el nivel de los códigos preestablecidos por las normas idiomáticas, del acervo lexical o el modo sintáctico con el que los usuarios practican el idioma en la cotidianidad; actos que impulsaran a breve plazo los cambios normativos necesarios para mantener dichos códigos al día. Alli en esas categorías los dos polos de un proceso dialéctico donde lo establecido convencionalmente por un grupo social, constantemente se muta a partir de la experiencia de la parte o el total del colectivo.

Por ende el lenguaje no es posible entenderlo sólo como instrumento, pues es tanto forma como contenido, es tanto significante como significado, es tanto fenómeno como esencia. De allí que el lenguaje, si bien es la representación del pensamiento de una época, es también su propia manifestación; en definitiva la expresión de su tiempo. 
Pero la referencia a la lingüistica, no debe inducir a sospechar que sólo considero o se considera lenguaje al empleado en la comunicación verbal, sino que el lenguaje está presente en toda praxis comunicacional, en todo fenómeno cultural y por ende en arquitectura. Una clara alusión a ello es la que nos ofrece Umberto Eco al exponer: "Si la semiótica no es solamente la ciencia de los signos reconocidos en cuanto a tales, sino que se puede considerar igualmente como la ciencia que estudia todos los fenómenos culturales como si fueran sistemas de signos - partiendo de la hipótesis que en realidad todos los fenómenos culturales son sistemas de signos, o sea, que cultura esencialmente es comunicación - uno de los sectores en el que la semiótica encuentra mayores dificultades, por la índole de la realidad que se pretende captar, es el de la arquitectura".(2).

Sin duda en estas últimas décadas los dos libros de mayor peso y difusión en el campo teórico de la arquitectura, han sido: "Complejidad y contradicción en la arquitectura" de Robert Venturi y "La arquitectura de la ciudad" de Aldo Rossi. En ambos, a pesar de sus radicales diferencias, se plantean los problemas de tipología y lenguaje en arquitectura, a la luz de los sistemas de formas y de los sistemas de significación. Comprendiendo así la arquitectura como un fenómeno perfectamente analizable como lenguaje.

Por supuesto esto no son sólo suposiciones, pues las explícitas alusiones al caso del texto de Rossi no es casual, sino por el contrario intencional, asi en su introducción se expone que: "El significado de los elementos permanentes en el estudio de la ciudad puede ser comparado con el que tienen en la lengua; es evidente que el estudio de la ciudad presenta analogías con el de la lingüistica, sobre todo por la complejidad de los procesos de modificación y por las permanen. cias.

Los puntos fijados por De Saussure para el desarrollo de la lingüística, podrían ser transpuestos como programa para el desarrollo de la ciencia urbana: descripción e historia de las ciudades existentes, investigación de las fuerzas que están en juego de modo permanente y universal en todos los hechos urbanos. $Y$, naturalmente, su necesidad de limitarse y definirse'.(3).

El libro de Venturi, también tiene claras referencias a la consideración del lenguaje en arquitectura, pero por estrategia de la exposición reservo su análisis para después.

\section{LA NORMA Y LA REFORMA}

La explicación de evolución histórica ha inducido a muchos a segmentar dos momentos del proceso que usualmente se identifican como situación y proyecto. El primero señala el total de lo existente en la actualidad, el segundo es la propuesta de carácter inmediato o mediato en pro de superar la situación. Dadas estas características que podriamos denominar meta-históricas, pues están presentes en todo tiempo, es posible entender dos conceptos de uso frecuente en los estudios del arte, como lo son clasicismo y vanguardia: donde lo clásico indicará el reconocimiento general a un acertado modo de hacer o al acopio de experiencias que depuradas y decantadas en el tiempo. Un modo de hacer, que a pesar que ha soportado el embate de diversas críticas, permanece en vigencia. Lo clásico es sin duda tradición, una tabla de valores comunes indiscutibles para una mayoría social, un cuerpo doctrinal perfectamente asimilado por el colectivo cultural, con independencia del grado de conciencia con el que la colectividad pondera lo realizado. Pero, como es por todos conocido, no siempre toda aseveración es totalmente compartida, por ende la idea de consenso absoluto es ilusoria e irreal, pues el disentir es propio del ser..., más aún si se trata de un sujeto creativo; imbuido de un afán renovador; por estas causas surgen las circunstancias propicias donde se gesta la vanguardia, que aspira mutar lo pautado, que ambiciona liderizar el cambio. Como siempre la vanguardia en oposición a lo clásico es una bandera de minorias que pretenden conquistar al resto, que de conseguirlo, se convierte paradójicamente en clásico. En otras palabras, podemos encontrar que en un determinado momento histórico algo que es vanguardia, al poco tiempo pasa a ser clásico pues se ha incorporado a los valores de un común denominador cultural.

Ahora bien, si pretendiéramos caracterizar la producción artística en nuestro siglo, diríamos que ella es la expresión de una extensa gama de teorías que desean hacer "manifiesta" su oposición a la práctica inmediatamente anterior o a la práctica que asume una o varias de las teorias anteriores, léase "historicismo". Nuestra centuria es una larga secuencia de vanguardias. Años de un profuso repertorio de "manifiestos", muchas veces más una declaración de guerra a los objetivos del movimiento que le precede, que la reflexión profunda que gesta nuevos caminos. Así cada manifiesto es a la vez un anti-manifiesto; asi cada movimiento es a la vez un anti-movimiento, asi cada sentido es a la vez un contra-sentido; así la ruptura con la tradición 
se convierte en una tradición de rupturas, donde la excepción que confirma la regla pretende el rol sublime de ser regla que confirme toda excepción.

\section{MODERNIDAD - POSMODERNIDAD}

Hoy no conforme con acatar o desacatar las doctrinas peculiares de un determinado núcleo artístico, se lanza la ofensiva contra un conjunto de movimientos disímiles que por una operación simplificadora se los cataloga de modernos. En tal sentido, la normal necesidad de cambio asume actualmente el rótulo de posmodernidad para renegar de una modernidad, que por su heterogeneidad es imposible de acotar. Una posmodernidad que por su anti-modernidad es difícil de comprender.

Moderno es iel "cubismo" o el "subrealismo"?, moderno es ¿el "neoplasticismo" o el "futurismo"?, moderno es iel "dadaismo" o el "fauvismo"? moderno es ¿el "constructivismo" o el "expresionismo"? moderno es ila "gestalt" o el "action painting"?, moderno es ¿el "op-art" o el "pop-art"?, moderno es iel "neofigurativismo" o el "expresionismo abstracto"?... o ¿todos a la vez? De ser positiva la respuesta valdría la pena formular la pregunta: ¿lo posmoderno implica un rechazo a todas las manifestaciones anteriores? o ¿sólo algunas?... ¿cuáles? Para el caso específico de arquitectura, también los "ismos" son muchos... ila lucha es contra todos los de una etapa histórica? o sólo el objetivo se centra en ciertos personajes y/o teorías, para otra vez esgrimir la pregunta de ¿cuáles? Como vemos hasta que no sepamos que es lo que pretendemos superar, no podremos saber cuál es el "pos" que tratamos.

El único que bosqueja una acotación estilística ante la cual se reacciona parece ser Robert Stern que proclama lo siguiente: "La arquitectura moderna, como sabemos, está en crisis: por más que algunos de los principales arquitectos del Movimiento Moderno, como $P$. Rudolph, I. M. Pei y K. Roche, sigan produciendo nuevas obras importantes usando el lenguaje del International Style, tanto las formas como las teorías sobre las que ellos se basan, están siendo sistemáticamente puestas en duda - y a menudo rechazadas - por un número de jóvenes arquitectos que tratan de forjar bases filosóficas para la arquitectura, y una nueva forma de lenguaje que es descripta, a falta de un término mejor, como Posmodernismo"(4). Aunque es de advertir que la utilización de "posmodernismo" en vez de "posmoderno", puede aparejar aún más confusión dado que este término alude a "modernismo", un movimiento arquitectónico definido por una praxis catalana que dis- ta mucho del "International Style". De todos modos tampoco Stern no está muy conforme con la palabra pues dice: a falta de un término mejor.

Quizás el problema principal de los propios promotores de la posmodernidad, es el propio término que la define. Umberto Eco en sus "Apostillas a el nombre de la rosa", expone lo siguiente: "Desde 1965 hasta hoy han quedado definitivamente aclaradas dos ideas. Que se podía volver a la intriga incluso a través de citas de otras intrigas, y que las citas podian ser menos consoladoras que las intrigas citadas (el almanaque Bom. piani de 1972 se dedicó al Ritorno dell'intreccio, si bien a través de una nueva visita, al mismo tiempo irónica y admirativa, a Ponson de Terrail y a Eugène Sue, de la admiración sin mayor ironía de algunas páginas no. tables de Dumas). ¿Podía existir una novela no consoladora, suficientemente problemática, y sin embargo amena?

Serian los teóricos norteamericanos del postmodernismo quienes realizarian esa sutura, y recuperarian no sólo la intriga sino también la amenidad.

Desgraciadamente, "posmoderno" es un término que sirve para cualquier cosa. Tengo la impresión de que hoy se aplica a todo lo que le gusta a quien lo utiliza. Por otra parte, parece que se está intentando desplazarlo hacia atrás: al principio parecía aplicarse a ciertos escritores o artistas de los últimos veinte años, pero poco a poco ha llegado hasta comienzos de siglo, y aún más allá, y, como sigue deslizándose, la categoría de lo posmoderno no tardará en llegar hasta Homero.

Sin embargo, creo que el posmodernismo no es una tendencia que pueda circunscribirse cronológicamente, sino una categoría espiritual, mejor dicho un KuntswoIlen, una manera de hacer. Podríamos decir que cada época tiene su propio posmodernismo, asi como cada época tendría su propio manierismo (me pregunto, incluso, si posmodernismo no será el nombre moderno de Manierismo, categoría metahistórica). Creo que en todas las épocas se llega a momentos de crisis como los que describe Nietzche en la Segunda consideración intempestiva, cuando habla de los inconvenientes de los estudios históricos. El pasado nos condiciona, nos agobia, nos chantajea. La vanguardia histórica (pero aquí también hablaria de categoría metahistórica) intenta ajustar las cuentas con el pasado. La divisa futurista "abajo el claro de luna" es un programa típico de cada vanguardia, basta reemplazar el claro de luna con lo que corresponda. La vanguardia destruye el pasado, lo desfigura: Les demoiselles d'Avignon constituyen un gesto típico de vanguardia; después la vanguardia va 
más allá, una vez que ha destruido la figura, la anula, llega a lo abstracto, a lo informal, a la tela blanca, a la tela desgarrada, a la tela quemada; en arquitectura será del curtain wall (muro cortina), el edificio como estela, paralelepípedo puro; en literatura, la destrucción del flujo del discurso, hasta el collage estilo Bourroughs, hasta el silencio o la página en blanco; en música, el paso del atonalismo al ruido, al silencio absoluto (en este sentido, el primer Cage es moderno).

Pero llega el momento en que la vanguardia (lo moderno) no puede ir más allá, porque ya ha producido un metalenguaje que habla de sus imposibles textos (arte conceptual). La respuesta posmoderna a lo moderno consiste en reconocer que, puesto que el pasado no puede destruirse - su destrucción conduce al silencio-, lo que hay que hacer es volver a visitarlo; con ironía, sin ingenuidad"'(5).

Hoy frente a lo visto, el lenguaje posmoderno podría definirse como el lenguaje que disconforme con la modernidad, trata de romper las limitaciones que la definen. Es un lenguaje que en arquitectura al decir de Charles Jencks: "A veces procede de la yuxtaposición de lo nuevo y lo viejo como en el caso de la obra de James Stirling; ocasionalmente se basa en la divertida invención de lo viejo como en el caso de Robert Venturi y Hans Hollein; y también casi siempre hay algo extraño en todo ello".(6) Como es fácil de inferir, estos son los mismos argumentos de la posmodernidad que identificaba Eco: diversión e intriga. La pregunta sería si sólo a partir de estas premisas se constituye la superación de la actual modernidad o es a lo mejor que estamos aún a la espera de una verdadera vanguardia que con profundidad crítica vislumbre un cambio radical al tiempo presente y pretérito: donde un ideario cristalizado, un estilo, una regla, o un código represivo, no permite la innovación.

\section{EL LENGUAJE POSMODERNO}

En mi parecer quien asume por primera vez y con mayor claridad la definición del lenguaje anti-moderno y a posterior asumido por la posmodernidad es Robert Venturi, quien manifiesta que: "Los arquitectos no pueden permitir que sean intimados por el lenguaje puritano moral de la arquitectura moderna. Prefiero los elementos híbridos a los "puros", los comprometidos a los "limpios", los distorsionados a los "rectos", los ambiguos a los "articulados", los tergiversados que a la vez son impersonales, a los aburridos que a la vez son "interesantes", los convencionales a los "diseñados", los integradores a los "excluyentes", los redundantes a los sencillos, los reminiscentes que a la vez son innovadores, los irregulares y equívocos a los directos y claros. Defiendo la vitalidad confusa frente a la unidad transparente. Acepto la falta de lógica y proclamo la dualidad.
Defiendo la riqueza de significados en vez de la claridad de significados; la función implícita a la vez que la explícita. Prefiero "esto y lo otro", a "o esto o lo otro", el blanco y el negro, y algunas veces el gris, al negro o al blanco. Una arquitectura válida evoca muchos niveles de significados y se centra en muchos puntos: su espacio y sus elementos se leen y funcionan de varias maneras a la vez.

Pero una arquitectura de la complejidad y la contradicción tiene que servir especialmente al conjunto; su verdad debe estar en su totalidad en sus implicaciones. Debe incorporar la unidad difícil de la inclusión en vez de la unidad fácil de la exclusión. Más no es menor"(7).

De su texto, es posible extraer una tabla de dicotomías, que al igual que las categorías propuestas por Wölfflin para distinguir lo clásico de lo barroco (7), pudieran establecer las antinomias que nos permitieran contraponer la modernidad de la posmodernidad. Asi en sintesis es factible concluir con el esquema siguiente:

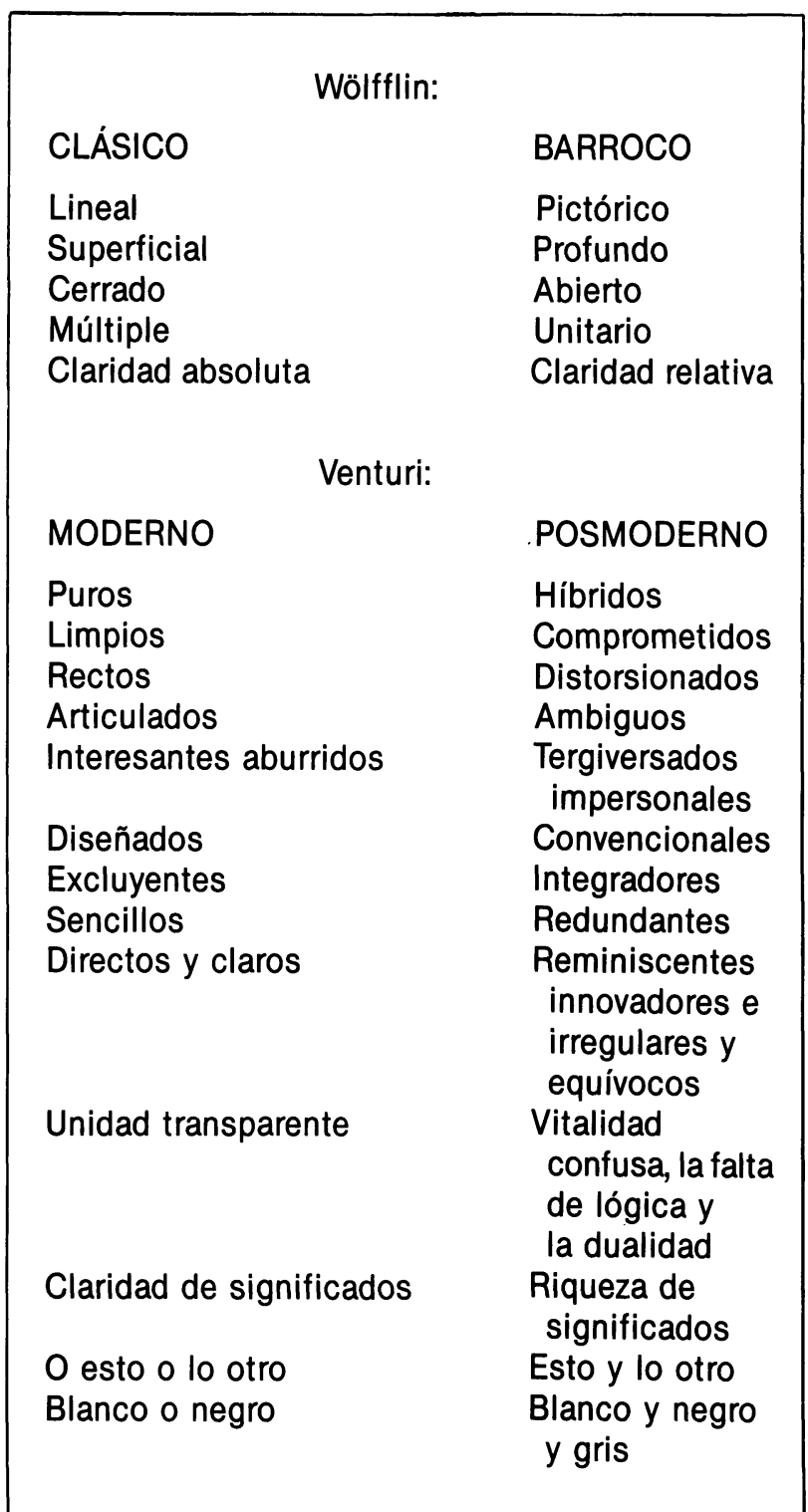


Pero sin dudas las prédicas de la posmodernidad no se agotan en estas dicotomias que sustantivarán nuevas morfologías. En discursos recientes es posible también establecer otras oposiciones que radicalizan más aún las polaridades teóricas antes descritas, ellas son los conceptos de:

La axiomática y la axiología

La pragmática y el valor variable.

Arquitectura en función social

Autonomía de la arquitectura.

Integración de las artes

Independencia del arte arquitectónico.

Arquitectura internacional

Arquitectura nacional o transnacional.

El texto innovador

El arraigo al contexto.

Ahistoricismo

Vernacularidad.

Lógica

Espontaneidad.

Innovación o renovación

Revival o restauración.

Evolución o revolución

Involución conservadora.

Los tratados maltratados

Los tratados retratados.

El pato

El tinglado.

La verdad constructiva

La verdad decorada.

La esperanza tecno-científica

La esperanza del lenguaje.

Prefabricación

Informática.

Racionalismo europeo

Empirismo norteamericano.

Clasicismo

Manierismo.

\section{CUANDO EL PASADO NOS ALCANZA}

Hoy, abrumados por las mutaciones y variaciones que constantemente se gestan, más como producto de artificiales intercambios de información controlada, que por una comunicación dialéctica, podemos observar el uso y el abuso de signos que acarrean un rápido desgaste frente a un devorador consumismo. Hoy la imagen de la empresa desea estar descrita por unas imágenes nuevas o que representen juventud, por más que deban de engavetar sus cien años de soledad en el ramo. Hoy los léxicos se agotan en el mercado popular de la publicidad, y hoy los lenguajes deben mantener su novedad aunque para ello recurran a formas perimidas del pasado. Para estar al día debemos sumergirnos en el baúl de la abuelita, desempolvar decrépitos retratos y con necrofílico humor reciclar sus significados.

Hoy Jencks habla de posmodernidad como la arquitectura que vino del "lenguaje", y como tal no la arquitectura del cambio, sino la arquitectura del intercambio o del recambio, de la polisemia comercial, que combate con otra arquitectura tanto a la moderna en sí, como a otra que él cataloga como ultra-moderna o tardomoderna; léase: “Pelli y Hardy/Holsman/Pheiffer'(8).

Hoy hasta la propia arquitectura se ve inmersa en un mar de rótulos, que más allá de definir estilísticas, es un desmedido afán por adjetivarse con meros títulos distintivos que avalen la novedad, asi en esa ruta podríamos llegar a encontrarnos con: el neovanguardismo, la retromodernidad, el suprarevival, el francoprogresista, el promanierismo, el protoclasicismo, o lo criptocontemporáneo. Términos que por su vacio semántico nos llevarian a la pura retórica. Un vacío que no es la nada, sino que está lleno de nada y por ende no admite nada más.

Hoy para muchos el hombre es comparable al "Angel de la historia", aquel que define Walter Benjamín cuando decia: "Hay un cuadro de Klee que se titula Angelus Novus. Se ve en él un ángel al parecer en el momento de alejarse de algo sobre lo cual clava la mirada. Tiene los ojos desencajados, la boca abierta y las alas tendidas. El ángel de la historia debe tener ese aspecto. Su cara está vuelta hacia el pasado. En lo que para nosotros aparece como una cadena de acontecimientos, él ve una catástrofe única, que acumula sin cesar ruina sobre ruina y se las arroja a sus pies. El ángel quisiera detenerse, despertar a los muertos y recomponer lo despedazado. Pero una tormenta desciende del Paraiso y se arremolina en sus alas y es tan fuerte que el ángel no puede plegarlas. Esta tempestad lo arrastra irresistiblemente hacia el futuro, al cual vuelve las espaldas, mientras el cúmulo de ruinas sube ante él hacia el cielo. Tal tempestad es lo que llamamos progreso"'(9). De ello podemos inferir mediante el recurso metafórico, que el hábitat construido hasta hace poco en función de las banderas del progreso, es producto de una evolución ahistórica, que para acelerar su desarrollo despejó de recuerdos el camino. Asi Paolo Portoghesi en su libro "Angel de la historia" que alude explícitamente a lo referido expone que él mismo está "dedicado a las nuevas generaciones de arquitectos que, volviendo a poner en circulación en los canales desecados el humor sanguíneo de la historia, han alejado animosamente la obsesión de la historia, preci- 
samente la de quien ha pretendido inútilmente que la arquitectura se despojase de todas las convenciones y las formas que han acompañado su camino a lo largo de los siglos para encontrarse después muda e impotente frente a la disgregación de la ciudad'. Si bien estos textos son de innegable importancia para corregir errores del presente por una defectuosa comprensión del pasado, así mismo debemos agregar que el mañana necesita de algo más que memoria arquitectónica. Que a la vez que no hay progreso sin historia, también es cierto que no hay historia sin progreso. De allí que los ángeles, que ni humanos ni divinos, deberán de acostumbrarse a aobservar las tempestades que dispone el hombre ante las propuestas de Dios(10).

Hoy, como siempre, el camino es la creación, la imaginación, el proponer la utopía como el espacio deseado y alcanzable en función de superar las restricciones ficticias que la reacción acostumbra a imponernos. Basta de adjetivos novedosos que sirven hasta para maquillar a los temerosos del cambio. El poeta Hugo Figueroa Bret en el primer verso de su poemario "Genital" asevera: |

\section{"Todo tiene ese espacio y el sitio prometido menos el hombre}

que es a quien promete"

y otro poeta, crítico de arte, y ensayista, Aldo Pellegrini en los años 50, decia: "... lo poético no reside sólo en la palabra; es una manera de actuar, es una manera de estar en el mundo y convivir con seres y cosas. El lenguaje poético en sus distintas formas (forma plástica, forma verbal, forma musical) no hace más que objetivar de un modo comunicable, mediante los signos propios de cada lenguaje particular, esa fuerza expansiva de lo vital.
Abierto el camino de la libertad por la poesía, se establece su acción subversiva. La poesía se convierte entonces en instrumento de lucha en pro de una condición humana en consonancia con las aspiraciones totales del hombre. Ceder a la exigencia de la poesía significa romper las ataduras creadas por el mundo cerrado de lo convencional"'(11).

Por ende es inadmisible cierta esterilidad teórica del momento, que ha traido como consecuencia el colmar el vacio dejado por la creatividad con una gimnasia intelectual, o con una lúdica conceptual, propia del formalismo intrascendente. Sin ir más lejos, en el prólogo del libro: "Los Tratados de Arquitectura" de Dora Wiebenson y que escribiera Adolf Placzek, dice lo siguiente: "Pero para la pragma el arquitecto necesita la theoría: los venerados órdenes, la búsqueda incesante de las proporciones ideales, los conceptos de simetría, armonía y perfección"'(12). Una receta que ni Serlio se atrevería a formular.

Hoy, todo lo planteado no puede, ni debe considerarse una conclusión, sino más bien una propuesta para profundizar el análisis sistemático de la modernidad y posmodernidad, para asumir con plena conciencia nuestro compromiso con el presente. Hoy es época de ir tras la buena arquitectura y no detrás de algún estilo o manera arquitectónica.

Estamos a poco más de un mes del comienzo de la última década... del último siglo... del último milenio, la fecha como todas las fechas es propicia para que concretamente asumamos el compromiso de cambio, sin los viejos lenguajes del despropósito y con el recuerdo que el hombre, a semejanza de Dios, es verbo y el verbo en última y vital instancia es acción, es hacer.

\section{TEXTOS CITADOS}

(1) SAUSSURE, Ferdinand de. Curso de lingüística ge. neral. Buenos Aires. Editorial Losada, p. 63, 1945 (1916).

(2) ECO, Umberto. La estructura ausente. Barcelona. Editorial Lumen, p. 323, 1972 (1968).

(3) ROSSI, Aldo. La arquitectura de la ciudad. BarceIona. Editorial Gustavo Gili, pp. 52-53, 3. ${ }^{a}$ ed. 1976 (1966).

(4) STERN, Robert. "Después del Movimiento Moderno". Sumarios 42: El posmodernismo ¿después o antes? Buenos Aires, abril 1980.

(5) ECO, Umberto. Apostillas a el nombre de la rosa. Barcelona. Editorial Lumen, p. 71, 1984 (1983).

(6) JENCKS, Charles. El lenguaje de la arquitectura posmoderna. Barcelona. Editorial Gustavo Gili, p. 5, 2. ${ }^{a}$ ed. 1978 (1977)
(7) VENTURI, Robert. Complejidad y contradicción en la arquitectura. Barcelona. Editorial Gustavo Gili, p. 26, 3. ${ }^{a}$ ed. 1984 (1966).

(8) JENCKS, Charles. El lenguaje de la arquitectura posmoderna. Barcelona. Editorial Gustavo Gili, p. 6, 2. ${ }^{a}$ ed. 1978 (1977).

(9) BENJAMIN, Walter. Angelus Novus. Barcelona. Edhesa, p. 82, 1971.

(10) GARCIA, Andrés. “El ángel de la historia”. Opción 5, p. 193, Maracaibo 1986.

(11) PELLEGRINI, Aldo. Para contribuir a la confusión general. Buenos Aires. Editorial Nueva Visión, p. 26, 1969.

(12) WEBENSON, Dora. Los tratados de arquitectura. Madrid. Hemmann Blume, p. 9, 1988. 